\title{
Comparison of the Shaping Ability of ProTaper GOLD, WaveOne GOLD, and TruNatomy in Simulated Double- curved Canals
}

\section{HyeWon Kim}

Wonkwang University

Su-Jin Jeon

Wonkwang University

Min-Seock Seo ( $\nabla$ profee@naver.com )

Wonkwang University https://orcid.org/0000-0001-7203-7775

\section{Research article}

Keywords: Root canal preparation, Canal transportation, Preparation time, Simulated canals, ProTaper GOLD, WaveOne GOLD, TruNatomy

Posted Date: February 4th, 2021

DOI: https://doi.org/10.21203/rs.3.rs-173699/v1

License: (1) This work is licensed under a Creative Commons Attribution 4.0 International License. Read Full License 


\section{Abstract}

Background: In root canal preparations, it is important to maintain the original canal shape. However, it is difficult to accomplish this, especially due to the complex canal anatomy. This study aimed to compare the shaping ability of the ProTaper GOLD, WaveOne GOLD, and newly developed TruNatomy in simulated Sshaped canals.

Materials and methods: The root canals of $60 \mathrm{~S}$-shaped resin blocks were dyed using ink and photographed. The blocks were then randomly divided into three groups: group ProTaper GOLD $(n=20)$, WaveOne GOLD $(n=20)$, and TruNatomy $(n=20)$. The simulated canals were instrumented according to the NiTi file system and photographed again after being dyed with red ink. The pre- and post-preparation images were superimposed, and the amount of resin removed from both the mesial and distal sides of the canal measured up to $9 \mathrm{~mm}$ from the apical terminus, with a $1 \mathrm{~mm}$ increment. The preparation time was also calculated. A paired t-test was used to determine the degree of deviation at different levels within the groups. To compare the degree of transportation at different levels between the groups, one-way ANOVA and Kruskal-Wallis tests were performed according to the normality.

Results: TruNatomy showed a significant deviation between the mesial and distal sides of the canal only in the coronal area at $6,7,8$, and $9 \mathrm{~mm}$ levels of the canal $(p<0.05)$. When comparing the amount of transportation in the 3 groups at 9 different levels, TruNatomy showed significantly less canal transportation than the other groups at the 3,5 , and 6 mm levels of the canal $(p<0.05)$, while ProTaper GOLD showed the largest amount of transportation in the apical curved area at the 2 and $3 \mathrm{~mm}$ levels $(p<0.05)$. TruNatomy removed less resin than other groups in all sections $(p<0.05)$, while ProTaper GOLD removed slightly more resin than WaveOne GOLD; however, there was no significant difference $(p=0.043)$. Shaping time was the least for TruNatomy, followed by the WaveOne GOLD and ProTaper GOLD $(p<0.05)$.

Conclusions: TruNatomy maintained the original canal curvature in S-shaped curved canals better than ProTaper GOLD and WaveOne GOLD.

\section{Background}

The main purpose of root canal preparation is to remove infected and necrotic pulp tissues in the canal. Simultaneously, it is also important to maintain the original shape of the root canal and preserve healthy root dentin for the long-term prognosis of teeth. However, the complex root canal anatomy makes shaping difficult, which can lead to insufficient disinfection and create procedural errors such as canal transportation, ledge, zip, and perforation $(1,2)$.

$\mathrm{NiTi}$ rotary file systems have been developed to increase flexibility and reduce iatrogenic errors with special alloys, different cross-sectional designs, cutting edges, and varying taper. Thermal treatment of NiTi alloy is also one of the manufacturing methods to improve the mechanical performance, by adjusting its transition temperature, while controlling the alloy microstructure. That is, the heat-treated NiTi alloy mainly contains Rphase or martensite, which is more flexible, while the conventional NiTi alloy contains austenite $(3,4)$. It has been reported that heat-treated NiTi files have significantly increased flexibility and cyclic fatigue resistance compared to conventional NiTi files(5-7). 
Gold heat-treated instruments, which are heat processed after the machining of the files, have been used to reduce machining process defects and to modify the crystalline phase structure(4). ProTaper GOLD (PTG, Dentsply Sirona, Ballaigues, Switzerland) and WaveOne GOLD (WOG, Dentsply Sirona) are representatives of gold heat-treated instruments. PTG files are rotary sequential systems with a convex triangular cross-section and a progressive taper. According to the manufacturer, PTG instruments have the same geometry as that of ProTaper Universal but manufactured with proprietary thermal treatment so that they have greater flexibility and resistance to cyclic fatigue $(8,9)$. WOG files are reciprocating single-file systems modified from WaveOne. WOG systems are improved by gold heat treatment and a new parallelogram cross-sectional design with two cutting edges $(6,10)$.

Recently, TruNatomy (TRN, Dentsply Sirona) file systems have been developed. These instruments are also manufactured using post-manufacturing thermal treatment. They have off-centered cross section with regressive taper, and just two cutting edges with a slim NiTi wire design, having $0.8 \mathrm{~mm}$ maximum flute diameter. According to the manufacturer, the combination of file design and heat treatment allows for greater flexibility and efficient shaping while removing only dentin, wherever clinically required $(11,12)$.

There have been several studies comparing the shaping ability of PTG and WOG with other NiTi file systems in curved canals, showing their superior performance at centering ability $(9,13,14)$. However, no study has evaluated the shaping ability of PTG, WOG, and newly developed TRN NiTi files in simulated canals. Several recent studies have compared the cyclic fatigue of TRN and other NiTi file systems $(12,15)$, but no studies have compared the shaping ability of TRN. Therefore, the aim of this study was to compare the shaping ability of PTG, WOG, and TRN in S-shaped simulated canals.

\section{Methods}

Sixty S-shaped simulated canals in clear resin blocks (Endo Training Bloc-S; Dentsply Sirona) were prepared. The simulated canals had a taper of 0.02 , an apical diameter of $0.15 \mathrm{~mm}$, a length of $16 \mathrm{~mm}$, an apical curvature of $20^{\circ}$ (3.5-mm radius), and a coronal curvature of $30^{\circ}$ (5-mm radius).

All canals were injected with black ink (Pelikan 400, Pelikan, Hannover, Germany R.F.A) and photographed using a digital camera (Nikon D5600, Nikon, Tokyo, Japan) in a constant position (Fig. 1A). Each canal was rinsed with copious amounts of distilled water before instrumentation. The resin blocks were numbered and randomly sorted into three groups according to the NiTi file systems. After instrumentation, the canals were injected with red ink (Pelikan 400, Pelikan, Hannover, Germany) and photographed again under the same conditions as before (Fig. 1B).

Root canal preparation was performed according to the manufacturer's recommendations for each system using an X-Smart Plus motor (Dentsply Maillefer, Ballaigues, Switzerland). All procedures were conducted by a second-year resident of the endodontic department, and each NiTi file was used in only one canal. The working length was set at $16 \mathrm{~mm}$, and patency was confirmed using\#10 K-file. All instruments were removed from the root canal after three in-and-out motions; the debris on the files cleaned with wet gauze, and the canal irrigated with $2 \mathrm{~mL}$ of distilled water each time.

\section{Group PTG}


The PTG S1(18./02), S2(20./04) and F1(20./07), F2(25./08) were used sequentially at $300 \mathrm{rpm}$ and 2 Ncm torque according to the manufacturer's instructions. After each instrument reached the working length, it was replaced with the next instrument.

\section{Group WOG}

The WOG Primary file (25./07) was used in the "WaveOne Gold" mode of the X-smart Plus motor until the working length was reached. According to the manufacturer's instructions, the file was gently advanced inwardly with $3 \mathrm{~mm}$ amplitude strokes.

\section{Group TRN}

The TRN prime file (26./04) was set at $500 \mathrm{rpm}$ and $1.5 \mathrm{Ncm}$ torque according to the manufacturer's instructions.

\section{Assessment of the canal preparation}

The pre- and post-preparation images were taken and saved as TIFF. These images were then imported into Photoshop software (Adobe Photoshop CS6, Adobe Systems Inc., San Jose, CA, USA) for superimposition (Fig. 2). The measurement lines perpendicular to the central axis of the canals were drawn at $1 \mathrm{~mm}$ intervals from the apical foramen using AutoCAD (AutoCAD LT 2021, Autodesk, San Rafael, CA, USA). The first measurement point was $1 \mathrm{~mm}$ from the apical terminus, and the last point was $9 \mathrm{~mm}$ from the apical terminus (Fig. 2D). The nine measurement points were divided into three sections, with apical curvature at 1$3 \mathrm{~mm}$ levels, coronal curvature at 4-7 mm levels, and straight section at 8-9 $\mathrm{mm}$ levels.

The amount of resin removed from the mesial and distal sides of the canals was measured. All measurements were performed under 10X magnification of the superimposed images by the operator of this study and another resident who was blinded to the experimental groups. The amount of transportation was calculated as the absolute value of the difference between the amount of resin removed from the mesial side and that removed from the distal side. The closer the transportation value was to zero, the better the ability to maintain the center.

The preparation time for each canal, including the time taken for active instrumentation, irrigation, cleaning the debris of the files, and changing the instruments, was recorded. Canal shaping was not performed in more than two canals per group in a day so that the operator's fatigue or skillfulness was excluded.

\section{Statistical analysis}

Statistical analyses were performed using SPSS software (SPSS Statistics 18; SPSS Inc., Chicago, IL, USA). The normality of the data was determined using the Shapiro-Wilk test. In order to determine in which direction the deviation occurred at each level, the values of the resin removed from the mesial and distal sides were compared using a paired t-test. To compare the transportation degree of the intergroup, one-way ANOVA and Kruskal-Wallis tests were performed according to the normality. The post hoc test was performed using Bonferroni's method. The significance level was set at $5 \%$. 


\section{Results}

Table 1 shows the mean amount of resin removed from the mesial and distal sides at 1-mm intervals in each group. When comparing the amount of resin removed from the mesial and distal sides, the PTG and WOG groups showed significant differences at all levels except at the $1 \mathrm{~mm}$ and $9 \mathrm{~mm}$ levels $(p<0.05)$. On the other hand, in the TRN group, there were significant differences in the amount of resin removed from mesial and distal sides only at $6,7,8$, and $9 \mathrm{~mm}$ levels $(p<0.05)$. Overall, in all three groups, the amount of resin removal was higher on the distal side at $1,2,3$, and $4 \mathrm{~mm}$, and in the rest of the range, there was more resin removal on the mesial side. When comparing the amount of transportation in the three groups at nine different levels, the TRN group showed less transportation than the other groups at 3, 5, and $6 \mathrm{~mm}$ levels ( $<<0.05)$. In addition, the PTG group showed the largest amount of transportation at the 2-and 3-mm levels $(p<0.05)$.

Table 1

Mean and standard deviation of the difference in removed resin materials from mesial and distal side

\section{Instruments}

ProTaper GOLD

WaveOne GOLD

TruNatomy

\begin{tabular}{|c|c|c|c|c|c|c|c|c|c|}
\hline level & Mesial & Distal & Difference & Mesial & Distal & Difference & Mesial & Distal & Differenc \\
\hline 1 & 0.103 & 0.111 & $\begin{array}{l}0.040 \pm \\
0.028\end{array}$ & 0.109 & 0.123 & $\begin{array}{l}0.033 \pm \\
0.025\end{array}$ & 0.107 & 0.115 & $\begin{array}{l}0.029 \pm \\
0.207\end{array}$ \\
\hline $\begin{array}{l}2 \\
a, c\end{array}$ & $0.085^{\star}$ & $0.186^{*}$ & $\begin{array}{l}0.108 \pm \\
0.049\end{array}$ & $0.115^{\star}$ & $0.154^{*}$ & $\begin{array}{l}0.041 \pm \\
0.029\end{array}$ & 0.101 & 0.107 & $\begin{array}{l}0.047 \pm \\
0.141\end{array}$ \\
\hline
\end{tabular}

\begin{tabular}{|c|c|c|c|c|c|c|c|c|}
\hline $\begin{array}{l}3 \\
a, b, c\end{array}$ & $0.105^{\star}$ & $0.216^{\star}$ & $\begin{array}{l}0.110 \pm \\
0.045\end{array}$ & $0.056 *$ & $0.171^{\star}$ & $\begin{array}{l}0.056 \pm \\
0.032\end{array}$ & 0.019 & 0.107 \\
\hline
\end{tabular}

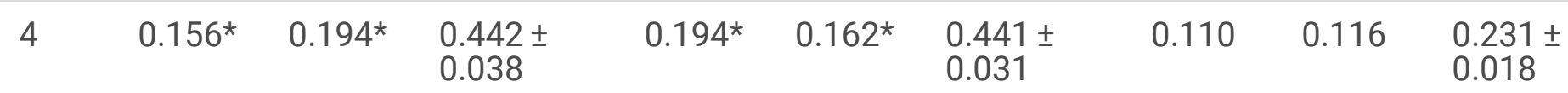

\begin{tabular}{|c|c|c|c|c|c|c|c|c|c|}
\hline $\begin{array}{l}5 \\
a, b, c\end{array}$ & $0.248 *$ & $0.163^{*}$ & $\begin{array}{l}0.086 \pm \\
0.042\end{array}$ & $0.268 *$ & $0.131 *$ & $\begin{array}{l}0.137 \pm \\
0.049\end{array}$ & 0.131 & 0.114 & $\begin{array}{l}0.033 \pm \\
0.029\end{array}$ \\
\hline
\end{tabular}

\begin{tabular}{|c|c|c|c|c|c|c|c|c|c|}
\hline $\begin{array}{l}6 \\
b, c\end{array}$ & $0.314^{\star}$ & 0.151 * & $\begin{array}{l}0.163 \\
0.047\end{array}$ & $0.314^{*}$ & $0.134^{\star}$ & 0.180 & $0.173 *$ & $0.112^{*}$ & $0.067 \pm$ \\
\hline
\end{tabular}

\begin{tabular}{|c|c|c|c|c|c|c|c|c|c|}
\hline 7 & $0.319 *$ & $0.176 *$ & $\begin{array}{l}0.143 \pm \\
0.075\end{array}$ & $0.275^{\star}$ & $0.162^{\star}$ & $\begin{array}{l}0.115 \pm \\
0.062\end{array}$ & $0.224^{*}$ & $0.126 *$ & $\begin{array}{l}0.105 \pm \\
0.055\end{array}$ \\
\hline 8 & $0.306 *$ & $0.216^{*}$ & $\begin{array}{l}0.103 \pm \\
0.067\end{array}$ & $0.276^{\star}$ & $0.229 *$ & $\begin{array}{l}0.078 \pm \\
0.053\end{array}$ & $0.243^{*}$ & 0.151 * & $\begin{array}{l}0.104 \\
0.056\end{array}$ \\
\hline 9 & 0.281 & 0.254 & $\begin{array}{l}0.069 \pm \\
0.046\end{array}$ & 0.256 & 0.249 & $\begin{array}{l}0.067 \pm \\
0.068\end{array}$ & 0.241 * & $0.171 *$ & $\begin{array}{l}0.082 \pm \\
0.054\end{array}$ \\
\hline
\end{tabular}

Statistically significant differences for transportation (difference): $a$, between PTG and WOG; b, between WOG and TRN; $c$, between PTG and TRN $(p<0.05)$

* Statistically significant difference when comparing the amount of resin removed in the mesial and distal walls $(p<0.05)$ 
The total amount of resin removed for each section, shown in Fig. 3, was calculated by adding the amount of resin removed from the mesial and distal sides. In the TRN group, less resin was removed than in the other groups, in all the sections $(p<0.05)$. In the entire range, resin removal was slightly more in the PTG group than the WOG group; however, the difference was not statistically significant $(p=0.043)$.

Table 2 shows the mean and standard deviation of the preparation time according to the instrument. The preparation time was significantly different for each group. The TRN group showed the least shaping time, followed by the WOG and PTG groups $(p<0.05)$.

Table 2

Means and standard deviations of canal preparation time (sec)

\begin{tabular}{|llll|}
\hline Parameter & PTG & WOG & TRN \\
\cline { 2 - 4 } & Mean \pm SD & Mean \pm SD & Mean \pm SD \\
\hline Time a,b,c & $245.75 \pm 22.03$ & $170.75 \pm 24.72$ & $139.10 \pm 24.54$ \\
\hline $\begin{array}{l}\text { Statistically significant differences for total } \\
\text { and TRN; } c \text {, between PTG and TRN }(p<0.05\end{array}$ & & \\
\hline
\end{tabular}

\section{Discussion}

Although NiTi files have continued to develop, it is still difficult to prepare S-shaped root canals. The aim of this study was to compare the shaping ability of PTG, WOG, and TRN in simulated S-shaped canals. As a result of the experiment, TRN showed significantly less transportation than the other groups at the $3 \mathrm{~mm}$ level from the apical curvature and 5 - and 6 -mm levels from the coronal curvature $(p<0.05)$. Even though it was not significant at 1, 4, and $7 \mathrm{~mm}$, TRN had a lesser tendency to cause transportation than that seen in other groups. TRN also removed the least resin in the apical and coronal curvature sections $(p<0.05)$.

To compare the shaping ability of NiTi files, resin blocks were used instead of the extracted human teeth in this study. Simulated canals in resin blocks provide standardized conditions for study and allow for direct comparison of pre- and post-instrumentation images. On the other hand, in human teeth, regular S-shaped root canals cannot be obtained. Although resin and tooth differ in their physical properties(16), numerous studies have used S-shaped simulated canals to compare the shaping ability of NiTi file systems $(14,17)$. Khalilak et al. also reported that the difference in apical transportation between extracted teeth and highhardness resin blocks was similar(18).

In all file systems, apical preparation size 25 was selected and a similar size of 26 was selected for TRN. In fact, the larger the apical preparation size, the more effective it is for debris removal and disinfection in the root canal(19). However, in a previous study, Akhlaghi et al. reported that the ability of the 25 apical size to reduce bacteria was not significantly different from that of the other groups with greater apical sizes(20). Furthermore, the more the apical size increases, the flexibility of the file decreases, so the risk of canal transportation also increases(21).

TRN, the newly developed file system, is manufactured using a slim NiTi wire with a $0.8 \mathrm{~mm}$ maximum flute diameter and an off-centered parallelogram cross-sectional design, in addition to a special heat treatment. 
TRN exhibits higher flexibility and superior canal-centering ability while preserving tooth structure(11).

Recently, there have been several studies on the fatigue resistance of TRN. Riyahi et al. reported that TRN had greater cyclic fatigue resistance than ProTaper NEXT and Twisted files (15). Elnaghy et al. also reported that TRN was more resistant to cyclic fatigue than the Vortex Blue and Race instruments in single and double curvature canals(12). These findings, related to the enhanced fatigue resistance, could be attributed to the special heat treatment of the alloy and the design of the instruments. Heat treatment changes the transformation behavior of the alloy and thus increases the flexibility of NiTi endodontic instruments(22). An off-centered parallelogram cross-sectional design and thin NiTi wire might have resulted in increasing cyclic fatigue resistance $(11,12,23)$.

According to the experimental results, in the TRN group, significant deviations occurred only in the coronal regions at $6,7,8$, and $9 \mathrm{~mm}(p<0.05)$. On the other hand, the other groups showed significant deviations in the rest of the range except for 1 and $9 \mathrm{~mm}(\mathrm{p}<0.05)$. In addition, when comparing the degree of transportation of the three groups, the TRN caused less transportation than that seen in the other groups and removed the least resin in the apical and coronal curvature. In other words, it can be said that the TRN had the best ability to maintain the center of canals in the double curvature area.

The fact that the least amount of resin was removed in the TRN group might be related to a small and regressive taper and slim NiTi wire design. In the present study, the apical taper of PTG, WOG, and TRN was $0.08,0.07$, and 0.04 , respectively. A significantly larger amount of resin was removed by PTG, compared to WOG, in the coronal curvature, and slightly higher in the apical curvature area. In addition, the PTG group showed more transportation than the other groups in the apical curvature $(p<0.05)$. This is consistent with a previous study showing that taper is a contributing factor in determining shaping ability $(17,24)$. The greater the taper in the apical area, the lesser the flexibility and higher the transportation degree, compared to other files of the same size(25).

In this study, PTG was used in continuous sequence with S1, S2, F1, and F2 according to the manufacturer's recommendations. A previous study showed similar anatomical outcomes between shaping a canal with ProTaper F2 using the single-file reciprocating technique and the conventional ProTaper full-sequence rotary approach(26). However, the single-file F2 ProTaper technique displayed significantly lower debridement ability in oval-shaped canals compared with the conventional ProTaper full sequence(27). In studies comparing the shaping ability of PTG with other single file systems, PTG has been used in the recommended sequence(28, 29).

The preparation time is dependent on the number of instruments used, the operator experience, and on the technique used. In the present study, the preparation time included the time taken for active instrumentation, changing instruments, cleaning the flutes of instruments, and irrigation(29). The TRN was the fastest file followed by WOG and PTG. In general, using a single file system takes less time than using several sequential rotary files. In addition, two single file systems, the WOG and TRN, showed significant differences, highlighting the better shaping efficiency of TRN. However, single file systems could prepare the canals relatively fast, so this difference might not be important in clinical situations(24).

\section{Conclusion}


Under the conditions of this study, it can be concluded that TRN files maintained the original canal shape in double-curved simulated canals. In addition, TRN prepared canals more efficiently and removed less resin than other heat-treated NiTi file systems. However, PTG with the largest apical taper showed more transportation in the apical curvature area.

\section{Abbreviations}

NiTi: nickel titanium, PTG: tapered GOLD, WOG: WaveOne GOLD, TRN: TruNatomy

\section{Declarations}

\section{Acknowledgements}

Not applicable.

\section{Author's contributions}

$\mathrm{KH}$ performed the laboratory experiments. $\mathrm{KH}$ and JS analyzed the data and evaluated the results. $\mathrm{KH}$ and SM wrote, reviewed, and proofread the manuscript. All the authors have read and approved the manuscript.

\section{Availability of data and materials}

The datasets used and analyzed during the study are available from the corresponding author upon reasonable request.

\section{Ethics approval and consent to participate}

Not applicable

\section{Funding}

The study was supported by Wonkwang University in 2021.

\section{Consent for publication}

Not applicable

\section{Competing interests}

The authors declare that they have no competing interests.

\section{References}

1. Peters OA. Current challenges and concepts in the preparation of root canal systems: a review. J Endod. 2004;30(8):559-67.

2. Jafarzadeh $\mathrm{H}$, Abbott PV. Ledge formation: review of a great challenge in endodontics. J Endod. 2007;33(10):1155-62. 
3. Pereira ÉSJ, Viana ACD, Buono VTL, Peters OA, de Azevedo Bahia MG. Behavior of nickel-titanium instruments manufactured with different thermal treatments. J Endod. 2015;41(1):67-71.

4. Zupanc J, Vahdat-Pajouh N, Schäfer E. New thermomechanically treated NiTi alloys-a review. Int Endod J. 2018;51(10):1088-103.

5. Shen Y, Zhou H-m, Zheng Y-f, Campbell L, Peng B, Haapasalo M. Metallurgical characterization of controlled memory wire nickel-titanium rotary instruments. J Endod. 2011;37(11):1566-71.

6. Özyürek T. Cyclic fatigue resistance of Reciproc, WaveOne, and WaveOne Gold nickel-titanium instruments. J Endod. 2016;42(10):1536-9.

7. Plotino G, Grande NM, Cotti E, Testarelli L, Gambarini G. Blue treatment enhances cyclic fatigue resistance of vortex nickel-titanium rotary files. J Endod. 2014;40(9):1451-3.

8. Hieawy A, Haapasalo M, Zhou H, Wang Z-j, Shen Y. Phase transformation behavior and resistance to bending and cyclic fatigue of ProTaper Gold and ProTaper Universal instruments. J Endod. 2015;41(7):1134-8.

9. Gagliardi J, Versiani MA, de Sousa-Neto MD, Plazas-Garzon A, Basrani B. Evaluation of the shaping characteristics of ProTaper Gold, ProTaper NEXT, and ProTaper Universal in curved canals. J Endod. 2015;41(10):1718-24.

10. Adıgüzel M, Capar ID. Comparison of cyclic fatigue resistance of WaveOne and WaveOne Gold small, primary, and large instruments. J Endod. 2017;43(4):623-7.

11. Dentsply Sirona. TruNatomy Brochure. Available at: https://www.dentsplysirona.com/en/explore/endodontics/trunatomy.html [Accessed April 26, 2019.]

12. Elnaghy AM, Elsaka SE, Mandorah AO. In vitro comparison of cyclic fatigue resistance of TruNatomy in single and double curvature canals compared with different nickel-titanium rotary instruments. BMC Oral Health. 2020;20(1):38.

13. Elashiry MM, Saber SE, Elashry SH. Comparison of shaping ability of different single-file systems using microcomputed tomography. Eur J Dent. 2020;14(1):70.

14. Özyürek T, Yılmaz K, Uslu G. Shaping ability of Reciproc, WaveOne GOLD, and HyFlex EDM single-file systems in simulated S-shaped canals. J Endod. 2017;43(5):805-9.

15. Riyahi AM, Bashiri A, Alshahrani K, Alshahrani S, Alamri HM, Al-Sudani D. Cyclic Fatigue Comparison of TruNatomy, Twisted File, and ProTaper Next Rotary Systems. Int Endod J. 2020(8):1-4

16. Schäfer E, Diez C, Hoppe W, Tepel J. Roentgenographic investigation of frequency and degree of canal curvatures in human permanent teeth. J Endod. 2002;28(3):211-6.

17. Bonaccorso A, Cantatore G, Condorelli GG, Schäfer E, Tripi TR. Shaping ability of four nickel-titanium rotary instruments in simulated S-shaped canals. J Endod. 2009;35(6):883-6.

18. Khalilak Z, Fallahdoost A, Dadresanfar B, Rezvani G. Comparison of extracted teeth and simulated resin blocks on apical canal transportation. Iran Endod J. 2008;3(4):109.

19. de Gregorio C, Arias A, Navarrete N, del Rio V, Oltra E, Cohenca N. Effect of apical size and taper on volume of irrigant delivered at working length with apical negative pressure at different root curvatures. J Endod. 2013;39(1):119-24. 
20. Akhlaghi NM, Rahimifard N, Moshari A, Vatanpour M, Darmiani S. The effect of size and taper of apical preparation in reducing intra-canal bacteria: a quantitative SEM study. Iran Endod J. 2014;9(1):61.

21. Zhang, L., Luo, H. X., Zhou, X. D., Tan, H., \& Huang, D. M. The shaping effect of the combination of two rotary nickel-titanium instruments in simulated S-shaped canals. J Endod. 2008;34(4): 456-458.

22. Gutmann J, Gao Y. Alteration in the inherent metallic and surface properties of nickel-titanium root canal instruments to enhance performance, durability and safety: a focused review. Int Endod J. 2012;45(2):113-28.

23. Silva EJNL, Vieira VCG, Tameirão MDN, Belladonna FG, Neves AdA, Souza EM, et al. Quantitative transportation assessment in curved canals prepared with an off-centered rectangular design system. Braz. Oral Res. 2016;30(1):1-7.

24. Saleh AM, Gilani PV, Tavanafar S, Schäfer E. Shaping ability of 4 different single-file systems in simulated S-shaped canals. J Endod. 2015;41(4):548-52.

25. Schäfer E, Dzepina A, Danesh G. Bending properties of rotary nickel-titanium instruments. Oral Surg Oral Med Oral Pathol Oral Radiol Endod. 2003;96(6):757-63.

26. Paqué F, Zehnder M, De-Deus G. Microtomography-based comparison of reciprocating single-file F2 ProTaper technique versus rotary full sequence. J Endod. 2011;37(10):1394-7.

27. De-Deus G, Barino B, Zamolyi RQ, Souza E, Júnior AF, Fidel S, et al. Suboptimal debridement quality produced by the single-file F2 ProTaper technique in oval-shaped canals. J Endod. 2010;36(11):1897-900.

28. Berutti E, Chiandussi G, Paolino DS, Scotti N, Cantatore G, Castellucci A, et al. Canal shaping with WaveOne Primary reciprocating files and ProTaper system: a comparative study. J Endod. 2012;38(4):505-9.

29. Bürklein S, Hinschitza K, Dammaschke T, Schäfer E. Shaping ability and cleaning effectiveness of two single-file systems in severely curved root canals of extracted teeth: Reciproc and WaveOne versus Mtwo and ProTaper. Int Endod J. 2012;45(5):449-61.

\section{Figures}



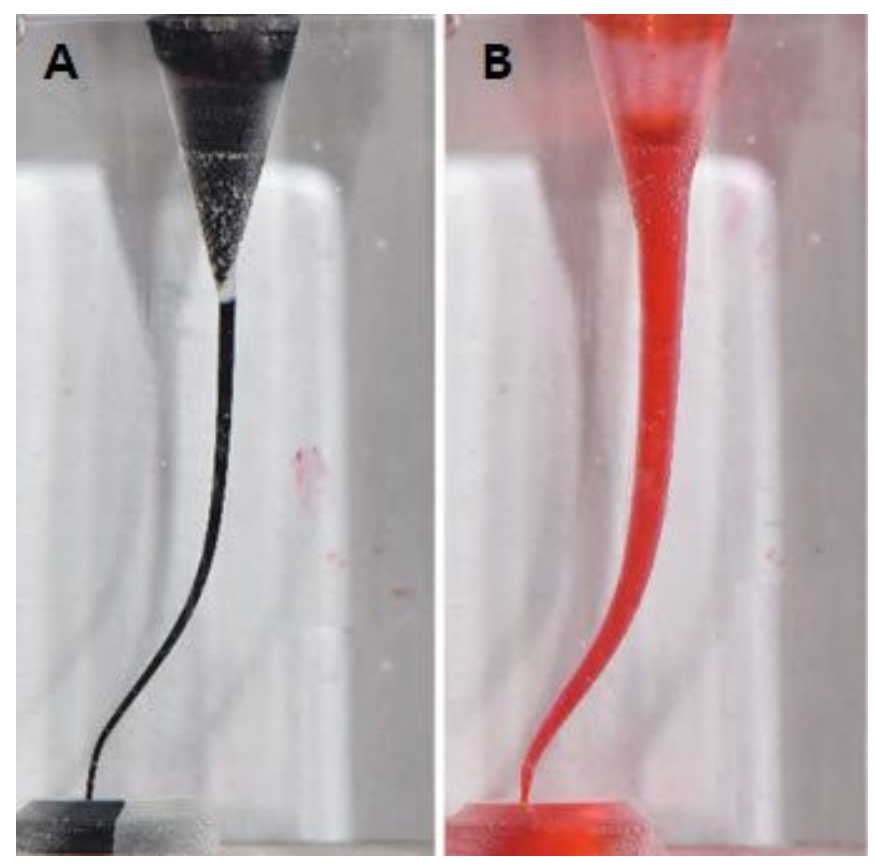

\section{Figure 1}

Resin block with S-shaped canal (A) injected black ink before instrumentation and (B) injected red ink after instrumentation

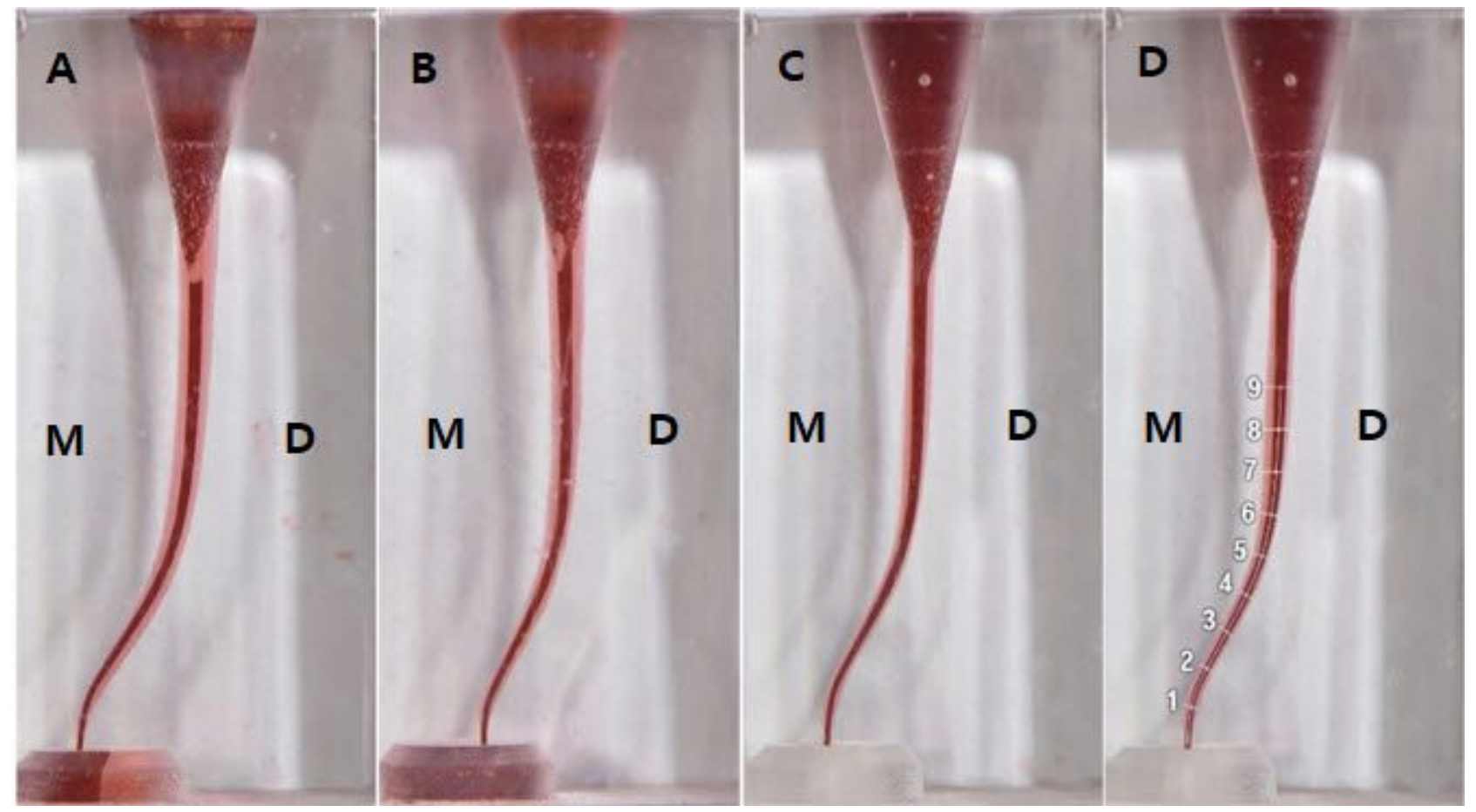

\section{Figure 2}

Superimposition images of pre- and post- instrumentation of each group (A) ProTaper GOLD, (B) WaveOne GOLD, (C) TruNatomy (D) Perpendicular line drawn to the canal central axis at $1 \mathrm{~mm}$ intervals from apical foramen. The first measurement point was $1 \mathrm{~mm}$ from the apical terminus, and the last point was $9 \mathrm{~mm}$ from the apical terminus. $M$, mesial; $D$, distal 


\section{Image not available with this version}

Figure 3

Mean and standardization of the total amount of removed resin for each range * Statistically significant difference when comparing the amount of removed resin $(p<0.05)$. 